\title{
The Internet of Things, Teamwork, and Service Projects
}

\author{
Ziye Wang \\ University of Washington Bothell \\ ziyewang@uw.edu
}

\author{
Deanna Kennedy \\ University of Washington Bothell \\ deannak@uw.edu
}

\begin{abstract}
The Internet of Things (IoT) has made inroads into many aspects of our lives. The application of IoT has enhanced our workplace with such technologies as RFID sensors for tracking and replenishing resources. Yet, there is limited research about the way human processes, and in particular, team processes are changed by IoT objects. Herein, we focus on sociotechnical systems theory in order to connect IoT and team processes, where IoT objects are differentiated based on functionality. We draw on the team process framework to clarify the type of taskoriented activities team members engage in over time as they collectively complete work projects. We connect different IoT objects to team processes and propose that the synergies may enhance team efficiencies and effectiveness. As well, we provide a real-world scenario about air conditioning service that illustrates how different IoT objects may be introduced to affect the team processes that apply.
\end{abstract}

\section{Introduction}

The Internet of Things (IoT) is increasingly revolutionizing the way we live by providing networked interconnections between our everyday objects [23]. The networking capabilities allow our everyday objects to share information and further, when intelligent systems are involved, appropriately react with decisions to improve our lives. For example, popular consumer products with IoT capabilities include refrigerators that can monitor internal inventory and create a grocery list on another personal device (e.g., cell phone), or potentially place an order over the internet with a grocer for pickup or delivery. Another product is the IoT enabled thermostat that can use wireless internet, Bluetooth sensors and apps to determine the optimal temperature depending on whether a person is home or away. Further, thermostats are being designed to have the capabilities to learn the user's home departure and arrival patterns to better predict and gauge temperature needs. While these inventions are now broadly sold to the consumer market, the creation of IoT enabled devices for our workplace has received less widespread recognition.

The application of IoT in the workplace has changed the way work unfolds in a number of industrial settings, from greenhouse and agriculture production for green deployment schemes [10] and precision agriculture methods [5], to classical production engineering, with automation and intelligent computation systems [18]. When IoT is applied in these operational settings, researchers have referred to the application as Industrial Internet of Things (IIoT). This terminology parallels the definition of Industrie 4.0 in Europe, and aligns with the Industrial Internet Consortium in the United States [18]. Although the term is supposed to address the broad spectrum of organizational operations, the main focus has been on manufacturing processes. Herein, we extend the concept and apply it to the service side of operations. There is limited research about the way IoT is applied in social systems [2], including business and service domains [20]. To extend this line of inquiry, we will use sociotechnical systems as the framework to compile the relationship between IoT and teamwork processes.

\section{Theory and Propositions}

\subsection{Sociotechnical Systems Theory}

In organizations, employees are often tasked with reconciling the social and technical properties of work environments. As such, sociotechnical systems theory (STS) provides a model for understanding the way employees balance these two independent, but linked aspects of work [17]. The STS model is a salient framework for considering the IoT and teamwork, because by introducing IoT devices to the workspace, organizations may not only change the way people work on a given task, but also the way people work together on teams. Moreover, evidence from STS literature shows that optimizing both social and technical systems jointly is more effective in 
improving performance, than benefiting either system alone [14] [21]. This motivates our investigation in how IoT can enhance teamwork and taskwork, social and technical sides of a service job, to help organizations attain greater performance. Next, we discuss the use of new IoT objects as the technical systems of interest and the benefit to social systems in terms of teamwork.

\subsection{Technical Systems: Industrial IoT Devices}

In 1999, Kevin Ashton may have been the firstever to mention the term "internet of things (IoT)" and he did so for the purpose of supply chain development purpose [1]. Years later, Forbes issued an article named after "The Internet of Things" addressing the implication of using RFID (radio-frequency identification) as a basis for IoT [1], that allows a system to fully automate collection of data [19]. In this system RFID information, could be read from a short distance and used to track items throughout the period of consumption [6]. One initial concept of internet of things was demonstrated and consolidated in the ITU Internet Reports - The Internet of Things, by the International Telecommunication Union in 2005. In this report, ubiquitous networks are called out where all devices are inclusively used and connected, particularly due to the widespread usage of mobile phones and internet. The report also presents the concept of "embedding short-range mobile transceivers into a wide array of additional gadgets and everyday items, enabling new forms of collaboration and communication between people and things, and between things themselves" [page 3], as the terminology for internet of things [11].

Even though the ideology of IoT has become more coherent, the definition remains uncertain due to the differences in the observational capabilities by objects in the Electronic Product Code as well as the extent to which autonomous objects can engage with each other over sensors and actuators [9]. As of 2015, the internet of things has been defined as networks that are built on the Internet, communicating by computers between objects and other objects [7]. As such, the concept and application of the internet of things continues to be refreshed and expanded over time.

The continued development of the internet of things itself has led the original term being applied to every contextual setting in which objects link to the internet. To focus our study, we seek to be more specific about the contextual boundaries of IoT application. As such, we are drawn to the term Industrial IoT (IIoT) to address our context. Yet, past attention to IIoT has primarily referred to the manufacturing side of operational processes, such as manufacturing procedure improvements. Herein, we focus on IIoT as it satisfies the service side of operations. As such, we suggest broadening the conceptual focus of IIoT, and use the term Operational IoT (OIoT) to specify the internet of things that covers both sides of operations management - manufacturing and service.

Recent research exploring the service side of IoT indicates the need for "the implementation and management of quality IoT services that meet the needs of users or applications" [24]. This idea motivates our case in terms of improving a service process, since it involves the interaction of different players: the client as the service receiver, the devices that connect with service team members, the environment with both the preexisting background and the artificial IoT network environment, and the human service team members.

To frame the IoT in our work, we use levels of IoT enabled objects described by Kortuem et al. that may be used to generalize the types of objects used for work [13]. At the simplest level, activity-aware objects are those objects that can record data during work activities such as when and for how long (i.e., time and duration) an activity occurs. For example, tracking the timing and duration of different construction labor tasks over time can be used to determine production trends and evaluate the need for additional resources. At the next level, policy-aware objects are those that objects that monitor and record data that are compared against a set of rules to send signals (e.g., alerts) or make decisions. For example, a machine may track machine quality data and when the variation in quality exceeds a certain level, then a signal is sent for maintenance and re-calibration. The highest level of objects includes process-aware objects that monitor and track data, but also interact with users to guide decisions that may affect task completion. For example, sensors may be used to monitor the way workers are using a tool in a particular context and offer suggestions about how long the tool should be used in that context or what other resources may be needed during use, and can offer subsequent activity scheduling based on the completion time, cost, and quality.

\subsection{Social Systems: Teamwork Processes}

As mentioned above, currently the application of IoT has been expanding across business domains. However, little is known about how human processes, and in particular, team processes are changed by IoT objects. Adopting the theory of socio-technical systems (STS), we suggest there is an interactive effect between social network of team members and IoT technology. 
We focus on the social system that is job oriented and contains work peers instead of a friendship system [3]. In this way, we keep the attention on the potential impact of IoT for teamwork process improvements that can benefit work performance efficiencies and performance effectiveness.

To understand how IoT objects may improve teamwork processes we use the team process framework by Marks et al. [15] to clarify the types of processes used by teams over time as they complete time-sensitive projects. The team process framework indicates that team members apply transition processes, action processes, and interpersonal processes as they work together on the task to achieve their goals. Herein, we focus on the way IoT objects address transition and action processes that are more taskoriented in nature. While IoT may also provide improvements in the area of interpersonal processes, the impact of IoT on team-oriented processes may be less obvious or direct and this complexity is left to future researchers. Thus, we focus on task-oriented processes in order to draw out likely areas for managerial insight.

Table 1 provides the sub-processes transition and action processes and their definitions. The transition sub-processes include: mission analysis, formulation, and planning; goal specification; and, strategy formulation. The action sub-processes include: monitoring progress towards goals; systems monitoring; monitoring and backup behavior; and, coordination.

Table 1. Teamwork processes

\begin{tabular}{|c|c|}
\hline $\begin{array}{l}\text { Process } \\
\text { Sub-process }\end{array}$ & Definition \\
\hline $\begin{array}{l}\text { Transition Process } \\
\text { Mission Analysis, } \\
\text { Formulation, and } \\
\text { Planning }\end{array}$ & $\begin{array}{l}\text { An assessment of the team's main } \\
\text { tasks and the circumstances under } \\
\text { which the team must perform the } \\
\text { tasks. }\end{array}$ \\
\hline $\begin{array}{l}\text { Transition Process } \\
\text { Goal Specification }\end{array}$ & $\begin{array}{l}\text { The assessment of the team's goals } \\
\text { and the identification and ranking or } \\
\text { prioritization of activities to reach } \\
\text { those goals. }\end{array}$ \\
\hline $\begin{array}{l}\text { Transition Process } \\
\text { Strategy } \\
\text { Formulation } \\
\end{array}$ & $\begin{array}{l}\text { The development and decisions for } \\
\text { an approach or approaches to achieve } \\
\text { the goals. }\end{array}$ \\
\hline $\begin{array}{l}\text { Action Process } \\
\text { Monitoring Progress } \\
\text { Toward Goals } \\
\end{array}$ & $\begin{array}{l}\text { The assessment of current task work } \\
\text { and what will be next steps in } \\
\text { achieving the goals. }\end{array}$ \\
\hline $\begin{array}{l}\text { Action Process } \\
\text { Systems Monitoring }\end{array}$ & $\begin{array}{l}\text { The assessment of the circumstances } \\
\text { impacting goal achievement } \\
\text { including what is happening within } \\
\text { internal and external systems. }\end{array}$ \\
\hline $\begin{array}{l}\text { Action Process Team } \\
\text { Monitoring and } \\
\text { Backup Behavior } \\
\end{array}$ & $\begin{array}{l}\text { The assessment and provision of } \\
\text { assistance to a teammate in order to } \\
\text { help activities be completed. }\end{array}$ \\
\hline $\begin{array}{l}\text { Action Process } \\
\text { Coordination }\end{array}$ & $\begin{array}{l}\text { The scheduling of interdependent } \\
\text { activities for goal achievement across } \\
\text { the team. }\end{array}$ \\
\hline
\end{tabular}

The expectation is that team members will iteratively attend to transition and action processes in order to complete the tasks of the project and ultimately, the team's goals. The iterative activities invoke the team to gather, assess, and react to information from within the team in response to the task, team needs, and external requirements. This need to gather and digest task information holds opportunities for IoT solutions.

The transition sub-processes attend to "how" and "what" the team needs to do in the future. That is, the transition sub-processes help the team plan to be efficient in performing the work. The action subprocesses address "how" and "what" and the team is doing now. As such, the action sub-processes may primarily determine how effective the team is in performing the work. Just as each sub-process serves a function in progressing the team towards its goals, there may be an IoT enabled device that has relevant functionality to augment or supplant the sub-process and enhance performance efficiency and effectiveness. Figure 1 presents the suggested connections of different types of IoT objects to pertinent team processes in order to enhance team outcomes. The discussion of these connections and propositions are presented below.

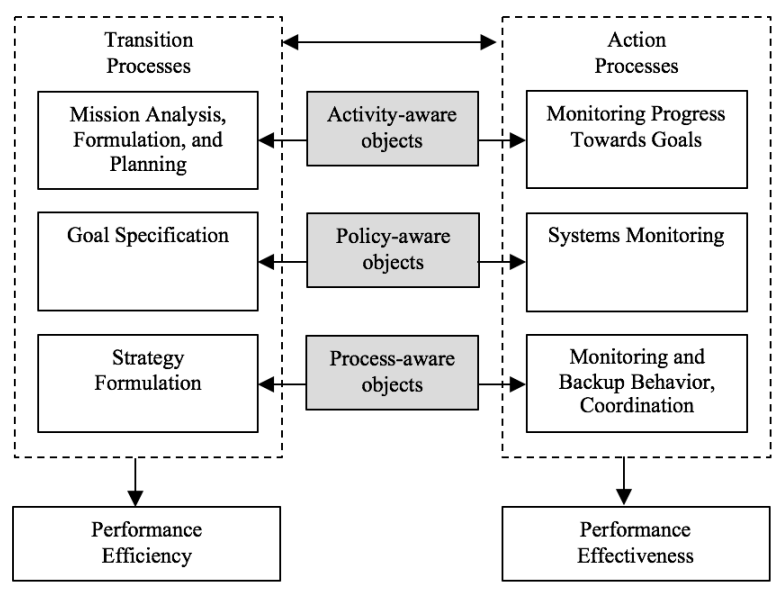

\section{Figure 1. loT devices and teamwork processes}

IoT solutions may provide assistance to transition teamwork sub-processes in the following ways. Activity-aware objects may be particularly relevant for mission analysis, formulation, and planning, because these objects can provide information about the conditions under which the team must perform. For instance, the IoT system can take requirements planning documentation and provide information about the availability of resources for the team. This may translate into better assessment of what, when and how 
the team needs to work on tasks during the project that ultimately improves the planning, and therefore the future efficiency, of the team.

The use of policy-aware objects may assist in goal specification. For example, teams may be alerted to a requirement that is out of specification for a machine, or beyond the expertise of assigned team members. The team can then decide how to respond to such alerts such as by acquiring a new machine or consulting services.

Finally, the use of process-aware objects for strategy formulation may help discover and implement contingency plans when certain material, labor, or process requirements change. For example, if a team member with the role of using special mechanical devices, such as a lift, is out sick or otherwise unavailable, then smart machines may be able to structurally adjust to be used by other members. As such, the team may be able to re-strategize and meet time requirements or compete the task early. Taken together, by pairing relevant IoT objects to transition sub-processes teams then process efficiencies may be gained. To formalize our argument, we offer the following propositions.

Proposition 1. Activity-aware objects enhance the transition sub-process of mission analysis, formulation, and planning that improves other team processes and ultimately, performance efficiency.

Proposition 2. Policy-aware objects may enhance the transition sub-process of goal specification that improves other team processes and ultimately, performance efficiency.

Proposition 3. Process-aware objects may enhance the transition sub-process of strategy formulation that improves other team processes and ultimately, performance efficiency.

To enhance the relationship between action subprocesses and performance effectiveness, the use of activity-aware objects may assist with the monitoring of progress towards goals. For instance, the use of sensors can indicate quality, duration, and completion level of task outcomes. Specifically, as activities are monitored and when certain progress or machinery output is indicated, then appropriate signals or actions may be planned by the team.

The use of policy-aware objects in systems monitoring may help teams react to conditions within and outside of the team. For example, a device that couples sensors and software may track quality of machining and send an alert when a part needs replacement or re-calibration to keep equipment functioning properly. As well, the sensor may make the team aware of breaks and downtime needed to reduce fatigue so that the team may meet quality specifications and reduce the time needed for re-work.

Also, the use of process-aware objects may improve the monitoring and backup behaviors by teams, as well as the coordination. The process-aware objects may be able to offer support and backup options in terms of identifying additional human or material resources that could be brought to bear in a particular task because they are currently idle and available. As well, the monitoring of performance can be translated into improved scheduling of tasks so that the right people are at the right place at the right time. These connections between IoT objects and action subprocesses lead to the following propositions.

Proposition 4. Activity-aware objects enhance the action sub-process of monitoring progress towards goals that improves other team processes and ultimately, performance effectiveness.

Proposition 5. Policy-aware objects may enhance the action sub-process of systems monitoring that improves other team processes and ultimately, performance effectiveness.

Proposition 6. Process-aware objects may enhance the action sub-processes of start monitoring and backup behaviors and coordination that improves other team processes and ultimately, performance effectiveness.

\section{IoT Application Potential}

To better demonstrate the application of IoT solutions to teamwork processes, we draw on the insights of an air conditioning manufacturer and service provider that has provided an extensive business case to the authors for study. We set up interviews with experts in relevant areas and followed a three phased approach to capturing information: (1) initial questionings provided descriptive stories of general service cases; (2) collaborative mapping of procedures and actions as flowcharts with experts; (3) and, discussion of IoT application ideas for feedback to revise details.

Air conditioning is a widely implemented system for both home and commercial purposes, yet there are specific differences in each consumer category. For example, home air conditioners are popularly small or portable units, with a limited cooling range. Yet, the air conditioner size and limitation in range also correspond to more reasonable costs, weight and space needs. Commercial air conditioners are designed for a larger cooling supply, and therefore cost more, are heavier in weight and take over larger spaces in order to provide adequate temperature or humidity adjustments within 
the large yet confined area. Based on building layout, there may be one outdoor unit connected to one indoor unit or a central air conditioning system with an outdoor unit linked to multiple indoor units. Central air conditioners are capable of reaching separate rooms and can provide independent room settings like home air conditioners but typically have a stronger power supply and air flow than home air conditioners.

Despite the simplicity used above, the commercial air conditioning system has many complex parts and functions. For example, precision air conditioners are typically equipped with a memory function so that when repowered, the air conditioner automatically restarts at settings before shut down, and temperature and humidity controls that maintain conditions within little tolerances and with long term stability. Figure 2 illustrates the refrigeration cycle of a typical air conditioner.

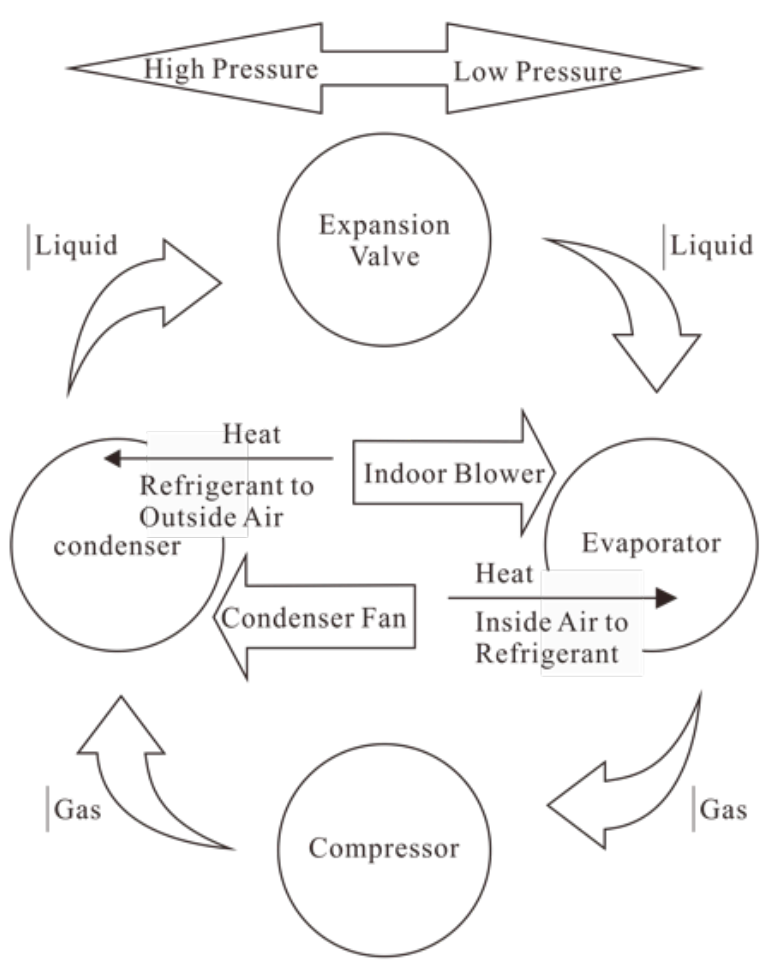

Figure 2. Air conditioner refrigeration cycle

When electricity is provided for the air conditioning system, the motor on the indoor blower will be started. The system will continuously compare the differences between sensed temperature and humidity and the values that are pre-set in order to determine how much cooling is needed. The compressor will be turned on to begin the circulation in the refrigeration system to produce cooling or heating. The refrigerant is transferred to the compressor as lowpressured gas where it will be compressed into a highpressured gas. The condenser takes in the gas, passing condensed high-pressure liquid to expansion valve, while releasing heat towards the outside through an outdoor condenser fan. Eventually the low-pressure liquid is sent to evaporator, the main cooling component to provide air to the indoor blower. The indoor blower works to evacuate indoor air passing through the evaporator for heat exchange. When the indoor temperature and humidity approaches the preset values, the compressor will pause while temperature and humidity sensors continue to operate and inspect the conditions.

The components noted within the cycle are critical to the performance of the unit and are a primary reason for service calls. The commercial systems are rarely serviced by individual employees, rather the service and maintenance of these systems is often a team effort. The work is also physically demanding and can include many trial and errors in terms of problem diagnosis. Moreover, given the magnitude of these systems and geographical dispersal of businesses, the service and maintenance of these machines is very costly. Given the physical and monetary demands of the job, we use the air condition service teams as a business case for indicating how different types of IoT objects may be implemented to affect different team processes and make process improvements.

\subsection{Air Conditioning Maintenance Project}

When the service team is called to address a problem with the commercial air conditioning system, they must evaluate, diagnose, and attempt to fix the problem. The team follows a flow chart that is generalized in Figure 3.

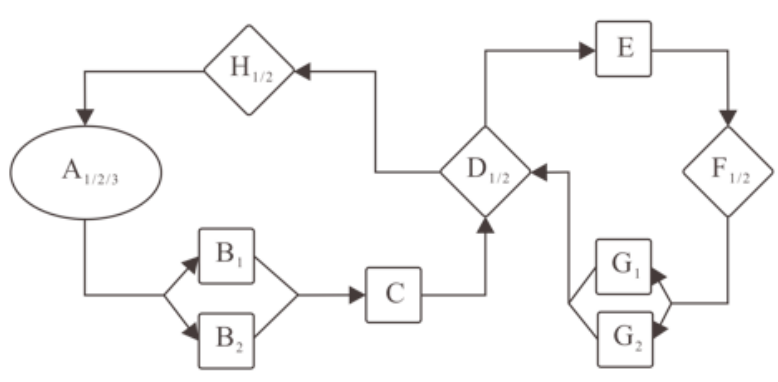

Figure 3. Flow chart of air conditioning maintenance project

Table 2 and Table 3 provide the description of steps in the flow chart. The problems can vary by 
categories: internal or external. Some of internal problems are 1) the leakage of refrigerant; 2) the damage on indoor and outdoor fans due to overuse, or 3) dirt intrusion in the outdoor condenser. To address these types of problems, the maintenance agency has to identify a service team and coordinate the transport the personnel with adequate equipment and materials to the place of the problems. Some external problems have to do with the circuit where the air conditioner system is connected and may include problems with 1) unstable voltage; 2) open circuit or short circuit; or 3) three-phase voltage unbalance and phase loss. All of these external problems can be due to various reasons. It takes more time to identify the source of external problems because it is highly possible that what caused the dysfunction of the air conditioning system is not due to any component of the machine itself, but due to external conditions.

\section{Table 2. Direction 1st half of flowchart}

\begin{tabular}{|l|l|}
\hline \multicolumn{2}{|l|}{ to R, until F $\left(1^{\text {st }}\right.$ decision after maintenance step $)$} \\
\hline Code & Function \\
\hline A1 & Receive of maintenance call, issue report \\
\hline B1 & Preparation of materials \\
\hline B2 & Preparation of labor \\
\hline C & Transportation to target \\
\hline D1 & Arrival at destination, first inspection \\
\hline E & Maintenance or repairing operation \\
\hline F1 & Fixed \\
\hline F2 & Could not be fixed \\
\hline
\end{tabular}

Table 3. Direction 2nd half of flowchart

\begin{tabular}{|l|l|}
\hline \multicolumn{2}{|l|}{ R to L, until A (complete this whole cycle once) } \\
\hline Code & Function \\
\hline G1 (by F1) & $\begin{array}{l}\text { Recording and reporting expenditures of material } \\
\text { \& labor }\end{array}$ \\
\hline & or \\
\hline G2 (by F2) & $\begin{array}{l}\text { Recording and reporting expenditures of material } \\
\text { \& labor, remaining problems }\end{array}$ \\
\hline D2 & Double check/further inspection \\
\hline H1 & $\begin{array}{l}\text { Confirmation of repair completion, Clean up, } \\
\text { Transportation back }\end{array}$ \\
\hline H2 & Reporting unsolvable issues \\
\hline A2 (by G1) & Issuing bill \\
\hline A3 (by G2) & Asking for another maintenance project \\
\hline
\end{tabular}

In previous publications, there has been a connection drawn between IoT and air conditioning systems [4]; however, the suggested application was limited to temperature and humidity functions and lacked attention to maintenance problems and service. Therefore, we extend previous work by focusing on the teamwork during service and maintenance, and the way IoT may specifically improve hardware component maintenance. Table 4 summarizes the application of IoT devices to different steps of the flow chart and the potential service team process improvement gained. These improvements are described in more detail below.

\section{Table 4. Summary of loT application and team service project}

\begin{tabular}{|c|c|c|c|}
\hline Point & $\begin{array}{l}\text { Device } \\
\text { Type }\end{array}$ & Aware-point & $\begin{array}{l}\text { Team Process } \\
\text { Improvement }\end{array}$ \\
\hline I & $\begin{array}{l}\text { Activity- } \\
\text { aware }\end{array}$ & $\begin{array}{l}\text { Monitoring } \\
\text { Activities }\end{array}$ & $\begin{array}{l}\text { Connecting all } \\
\text { surrounding sensors to } \\
\text { recognize, record and } \\
\text { report info and data } \\
\text { improves transition } \\
\text { process mission analysis, } \\
\text { formulation, and } \\
\text { planning }\end{array}$ \\
\hline $\mathrm{D} / \mathrm{E}$ & $\begin{array}{l}\text { Policy- } \\
\text { aware and } \\
\text { Process- } \\
\text { aware }\end{array}$ & $\begin{array}{l}\text { Reinforcing } \\
\text { Policy; } \\
\text { Making } \\
\text { Decisions } \\
\text { (internal) }\end{array}$ & $\begin{array}{l}\text { Receiving signals and to } \\
\text { operate repairs improves } \\
\text { transition processes of } \\
\text { goal specification and } \\
\text { strategy formulation } \\
\text { After repairing to acquire } \\
\text { signals to improve action } \\
\text { processes of monitoring } \\
\text { progress towards goals } \\
\text { and backup behaviors. }\end{array}$ \\
\hline $\mathrm{A}$ & $\begin{array}{l}\text { Policy- } \\
\text { aware }\end{array}$ & $\begin{array}{l}\text { Reinforcing } \\
\text { Policy } \\
\text { (external) }\end{array}$ & $\begin{array}{l}\text { Connecting to the circuit } \\
\text { and automatically } \\
\text { shutting down and } \\
\text { sending alarms when } \\
\text { applicable to improve } \\
\text { action process of system } \\
\text { monitoring }\end{array}$ \\
\hline
\end{tabular}

Figure 4 revises the flow chart for the maintenance project, with IoT devices implemented. Table 5 and Table 6 provide the steps of the revised flow chart.

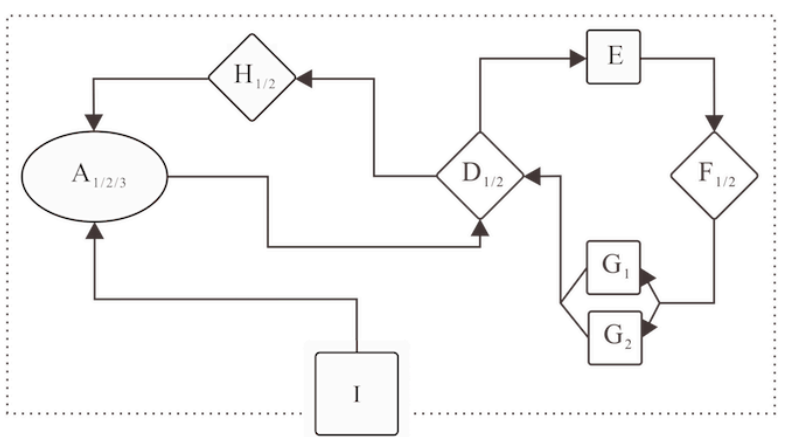

Figure 4. Flow Chart of air conditioning maintenance project with loT devices applied

The use of activity-aware objects may be pertinent at flow chart point $\mathrm{A}$, where the users, who mostly do not physically stay around the air conditioners, as well as the maintenance agency will be able to obtain the reports of functional use and issues. From this data, users or the service agency may determine whether there are mechanical problems that need to be solved 
through maintenance. For example, a device may be able to capture and report changes in the system functionality that an electrical expert may assess as a circuitry issue. Essentially the activity-aware objects are tacitly monitoring the system and passing the information on to the service team for the transition process of mission analysis, formulation, and planning. The data can help the team make quick decisions and timely determine what problem is occurring.

\section{Table 5. Revised 1st half of flowchart}

\begin{tabular}{|l|l|}
\hline \multicolumn{2}{|l|}{ L to $\mathrm{R}$, until $\mathrm{F}\left(1^{\text {st }}\right.$ decision after maintenance step $)$} \\
\hline Code & Function \\
\hline I & IoT devices monitoring, recording and reporting \\
\hline A1 & Receive of maintenance signal, issue report to office \\
\hline D1 & First inspection by local sensors, identifying issues \\
\hline E & Automatic maintenance or repairing operation \\
\hline F1 & Fixed \\
\hline F2 & Could not be fixed \\
\hline
\end{tabular}

Table 6. Revised 2 nd half of flowchart

\begin{tabular}{|l|l|}
\hline \multicolumn{2}{|l|}{ R to L, until I (complete this whole cycle once) } \\
\hline Code & Function \\
\hline G1 (by F1) & Recording and reporting expenditures \\
\hline & or \\
\hline G2 (by F2) & $\begin{array}{l}\text { Recording and reporting expenditures and } \\
\text { remaining problems }\end{array}$ \\
\hline D2 & Double check/further inspection \\
\hline J & Request for refilling of materials used \\
\hline A2 (by G1) & Issuing bill \\
\hline A3 (by G2) & Asking for another maintenance project \\
\hline I & IoT devices monitoring, recording and reporting \\
\hline
\end{tabular}

The use of policy-aware and process-aware objects may help at point $\mathrm{D} / \mathrm{E}$. That is, there can be devices with micro-mechanical arms or machinery design, and parts with tools. For example, if the object monitors certain areas or connections on the air conditioner, then the object may be able to detect leakage of refrigerant. If the object can also make decisions, then it can send out a signal for other machines to locate the exact place of leakage and cover it, while also pulling in additional refrigerant from backup blocks and adding it into circulation in order to offset the lost refrigerant. Such monitoring and alerting of problems may help the service team more efficiently run through transition processes of goal specification and strategy formulation in order prepare for the maintenance run.

Another example would be including an object that detects the significant reduction of refrigerating efficiency due to too much dirt in the outdoor condenser. When this is found, then a process-aware object may be able to handle the issue itself by starting ultrasound cleaning, initializing a pre-installed water tank to drop water in to clean the condenser, or using an auto spraying system to apply water and wash off the dirt to a drainage groove or tube. While some air conditioners may have such cleaning options, they rely on service technicians to work together in the application, assessment, and clean-up of such a process. Interestingly, the use of IoT devices in this scenario may not only help the service team be more effective during a maintenance run, the use of such devices may be able to handle the situation without the need for the team to be physical present. Thus, by acquiring signals the process-aware devices may be able improve the effectiveness of action processes including the monitoring progress towards goals and backup behaviors by helping the team with the work, or conducting the activity in their absence.

At point I, a policy-aware device may be implemented to improve action process of system monitoring. The team may use multiple journal or log recording devices to track specs or behaviors of the machine or surrounding environment. The devices can be constructed for different components, including thermostats readers, pressure meters, vibration meters, noise detectors, far infrared detectors, camera and voice recorders, data storing containers and so on. When abnormal signals are found, including schemes of internal or external issues, even natural resource disasters such as flood or fire, or animal violations such as rats or snakes, the devices automatically start to record any information that might be useful for further analysis, exchange data within the network of sensors and send out reports.

\subsection{Social Systems Side of Changes}

Considering the social system side of work, there are four general fields to investigate: 1) individual needs, characteristics, and abilities of people in the work system; 2) internal work system characteristics; 3) external environment of the work system; 4) support systems for that work system [3]. Using the scheme, we created about the application of IoT devices and set up we can analyze the possible changes.

In the teamwork process mapping, we believe that the application of IoT devices will impact the internal work system characteristics and result in a change to the individual needs and abilities of members. For example, the maintenance team members will face less pressure and perhaps less workload on service projects than what they previously needed during service operations. That is, the more integration of IoT devices, the more data transfer, analysis and action that may precede human effort. As well, the devices provide decision-making support that can preempt guesswork and increase team members' confidence in their actions. This, in turn, may increase team 
outcomes, such as team potency, satisfaction and wellbeing, that may create a virtuous cycle of performance.

\section{Implications}

In this study we focused on the application IoT in a service team context. This research extends the focus on Industrial IoT (IIoT), and may more appropriately be referred to as an application of Operational IoT (OIoT) because of attention to service processes. Our insights about the ways IoT devices with different functionality may offer service team improvement may also be relevant to other service scenarios. For instance, there can be a similar inspection, notification and adjustment IoT devices set up in power supply organization, such as power plants, and wind or solar farms. The functionality of IoT devices suggests an opportunity for managers to effectively supervise service teams and pre-emptively catch malfunctioning machinery. This concept can also be applied in automatic observatories, by adopting devices, including sensors, processors and machinery components, the human visit cycle will be reduced, along with reduction of labor costs, while in parallel, may create benefits with regards to workers' mental health from avoiding over exploitation under extreme circumstances or isolation.

\section{Implementation Challenges}

The implementation of IoT capabilities can be overshadowed by issues of privacy and cost. Indeed, Weber and Weber suggest that these are critical issues in IoT implementation because "an individual want to control access to his/her personal information" [page 41] [22]. Therefore, the privacy concern may occur in following circumstance: when the devices sensed signals in the surroundings, internal areas such as the components inside the machine or external areas such as the circuits of the confined room, they should have recorded and reported the information and data to headquarters. However, since the privacy exists between users and maintenance agents and the hierarchy of accessing and processing data and info should not be breached, the signal might not be passed on to maintenance agents.

With developing technologies, the costs of sensor networks have decreased [8]. However, we need to be aware of the energy costs occurring among wireless sensor networks [16]. These costs occur when the internet of things is built on networks that are consuming energy through connectivity, transmission and functioning, that makes the expenditures related to operations of the IoT devices significant enough to be evaluated and controlled. Previous research has been done, for example, in regards to construction vehicles [12]. Companies using construction vehicles need technology improvement based on IoT in order to monitor maintenance issues across geographical distributions. Therefore, more realistic cost analyses of building up networks are crucially awaiting discussions and experiments.

\section{Conclusion}

This work shows the potential of a socio-technical system, IoT object implementation and teamwork processes, that jointly improves work outcomes. The implementation of IoT sensors and devices for purposes of monitoring, data recording, analysis, and reporting can significantly improve the transition process in terms of the shortening the time for evaluating environment, diagnosing issues and setting up maintenance goals. As well, the proper combination of IoT sensors, devices and mechanisms leads to improvement of action processes. The machine or mechanics may be able to directly take action at process targets so that teams may operate maintenance projects with less intervention of manual labor. Throughout the maintenance project, the situation can be monitored and evaluated by IoT objects so that the quality control can also be turned over to autonomous agents. Therefore, in both transition and action processes, the efficiency and effectiveness improves with the involvement by IoT implementation, that ultimately could increase the performance of the current business process.

\section{References}

[1] K. Ashton, "That 'Internet of Things' Thing, in the real world things matter more than ideas", RFID Journal, 2009.

[2] L. Atzori, A. Iera, G. Morabito and M. Nitti, "The Social Internet of Things (SIoT) - When social networks meet the Internet of Things: Concept, architecture and network characterization", Computer Networks, 56(16), 2012, pp. 3594-3608.

[3] R. P. Bostrom and J. S. Heinen, "MIS Problems and Failures: A Socio-Technical Perspective, Part II: The Application of Socio-Technical Theory", MIS Quarterly, 1(4), 1977, pp.11-28.

[4] H. Chen, "Implementation of Textile Air Conditioning Intelligent Monitoring System Based on Internet of Things", International Journal of Smart Home, 9(12), 2015, pp. 267278. 
[5] F. J. Ferrández-Pastor, J. M. García-Chamizo, M. NietoHidalgo, J. Mora-Pascual and J. Mora-Martínez,

"Developing Ubiquitous Sensor Network Platform Using Internet of Things: Application in Precision Agriculture"

Sensors, Switzerland, 16(7), 2016. pp. 1-20

[6] J. Fildes, "Chips with everything", New Scientist, 176(2365), 2002, pp. 44-47.

[7] E. A. Fischer, "The Internet of Things: Frequently Asked Questions", Congressional Research Service, 2015, Summary.

[8] J. Gubbi, R. Buyya, S. Marusic and M. Palaniswami, "Internet of Things (IoT): A vision, architectural elements, and future directions", Future Generation Computer Systems, 29(7), 2013, pp. 1645-1660.

[9] S. Haller, "The Things in the Internet of Things", Paper presented at the Internet of Things Conference, Tokyo, Japan 2010, http://www.iot2010.org/.

[10] J. Huang, Y. Meng, X. Gong, Y. Liu and Q. Duan, "A Novel Deployment Scheme for Green Internet of Things", IEEE Internet of Things Journal, 1(2), 2014, pp. 196-205.

[11] ITU Strategy and Policy Unit (SPU), "ITU Internet Reports - The Internet of Things", International Telecommunication Union, Geneva, 2005.

[12] M. Jin, X. Zhou, E. Luo and X. Qing, "Industrial-QoSOriented Remote Wireless Communication Protocol for the Internet of Construction Vehicles", IEEE Transactions on Industrial Electronics, 62(11), 2015, pp. 7103-7113.

[13] G. Kortuem, F. Kawsar, V. Sundramoorthy and D. Fitton, "Smart objects as building blocks for the internet of things", IEEE Internet Computing, 14(1), 2010, pp. 44-51.

[14] E. E. Lawler, "The ultimate advantage: creating the high-involvement organization", Jossey-Bass, San Francisco, CA, USA, 1992.
[15] M. Marks, J. E. Mathieu and S. J. Zaccaro, "A temporally based framework and taxonomy of team purposes", Academy of Management Review, 26(3), 2001, pp. 356-376.

[16] R S. Misra and A. Jain, "Policy controlled selfconfiguration in unattended wireless sensor networks", Journal of Network and Computer Applications, 34(5), 2011, pp. $1530-1544$.

[17] W. A. Passmore, "Designing effective organizations: the sociotechnical systems perspective", Wiley, New York, NY, USA, 1988.

[18] A. Sadeghi, C. Wachsmann and M. Waidner, "Security and privacy challenges in industrial Internet of Things", 2015 52nd ACM/EDAC/IEEE Design Automation Conference, San Francisco, CA, USA. 2015, pp. 1-6.

[19] C. R. Schoenberger and B. Upbin, "The internet of things", Forbes Magazine, 169(6), 2002, pp. 155-160.

[20] P. Spiess, S. Karnouskos, D. Guinard, D. Savio, O. Baecker, L. M. Sá de Souza and V. Trifa, "SOA-based Integration of the Internet of Things in Enterprise Services", IEEE International Conference on Web Services, 2009, pp. 968-975.

[21] E. L. Trist and K. W. Bamforth, "Some social and psychological consequences of the long wall method of coalgetting”, Human Relations, 4(1), 1951, pp.3-38.

[22] R. H. Weber and R. Weber, "Internet of things - Legal Perspectives (Vol. 12)", Springer, New York, NY, USA, 2010 .

[23] F. Xia, L. T. Yang, L. Wang and A. Vinel, "Internet of Things", International Journal of Communication Systems, 25(9), 2012, pp. 1101-1102.

[24] L. Xu, W. He and S. Li, "Internet of Things in Industries: A Survey", IEEE Transactions on Industrial Informatics, 10(4), 2014, pp. 2233-2243. 